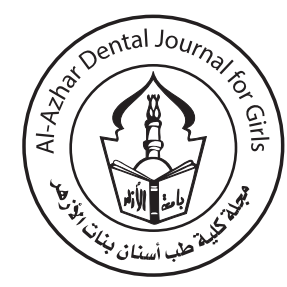

\title{
Evaluation of the effect of saliva contamination and cleaning methods on the surface free energy and shear bond strength of resin cements to zirconia ceramics
}

\author{
Aliaa F. Gadallah ${ }^{(1)}$, Inas T. Motawea ${ }^{(2)}$, Rania E. Bayoumi ${ }^{(3)}$
}

Codex : 45/1810

azhardentj@azhar.edu.eg

http://adjg.journals.ekb.eg

\section{KEYWORDS}

(CAD/CAM) zirconia ceramics, surface free energy, shear bond strength

\begin{abstract}
Objective: This study was designated to evaluate the effect of saliva contamination and cleaning methods on the surface free energy and the shear bond strength of resin cement to zirconia ceramics. Materials and Methods: A total of 80 samples were copy milled (CAD/CAM) from Zirconia blank. The samples were randomly divided into (4) groups $(n=20)$ according to method of cleaning. Group 1 (control): No saliva contamination,Group 2: The samples cleaned with distilled water,Group 3: The samples cleaned with ivoclean, Group4:The samples cleaned with re-sandblasting. Each group was subdivided into 2 subgroups according to the type of adhesive resin cement (Multilink Speed and RelyX Ultimate) used $(n=10)$. Each subgroup was further subdivided into two divisions according to the type of test (surface free energy and bond strength) performed ( $n=5)$. One-way analysis of variance ANOVA test and Tukey' post hoc test were done for comparing variables. Results: The control groups record the lowest mean contact angle value $\left(25.81^{\circ} \pm 1.76^{\circ}\right)$ and the highest mean surface free energy value $(107.57 \mathrm{mN} / \mathrm{m})$. While the group washed with water revealed the highest mean contact angle value $\left(39.04^{\circ} \pm 0.68^{\circ}\right)$ and the lowest mean surface free energy value $(98.58 \mathrm{mN} / \mathrm{m})$. Regarding shear bond strength the results showed that the highest shear bond strength value was recorded for the control group $(14.33 \pm 1.98 \& 13.73 \pm 1.33$ MPa), for Multi-link speed and Rely-X ultimate cement respectively, followed by resandblasting group, followed by ivoclean group, while the lowest shear bond strength value was recorded for the group washed with water $(10.9 \pm 0.53 \& 8.22 \pm 0.85 \mathrm{MPa})$. However, regardless of the cleaning protocol groups, Multi-link speed cement recorded a higher mean shear bond strength value than RelyX Ultimate cement. However these difference was statistically non-significant except for the group washed with water $(p=0.0003)$ as indicated by unpaired $t$ test. Failure modes for all groups were evaluated, failure modes was either adhesive, cohesive or mixed, with frequency ranging from 20 to $40 \%$ for each type of failure. The group washed with water showed that all
\end{abstract}

Paper extracted from Master Thesis titled "Evaluation of the effect of saliva contamination and cleaning methods on the surface free energy and shear bond strength of resin cement to zirconia ceramics"

1. Demonstrator, Dental Biomaterials Department, Faculty of Dental Medicine for Girls, Al-Azhar University, Egypt.

2. Professor, Head of, Dental Biomaterials Department, Faculty of Dental Medicine for Girls, Al-Azhar University, Egypt.

3. Lecturer, Dental Biomaterials Department, Faculty of Dental Medicine for Girls, Al-Azhar University, Egypt. 
of cases of failure were of the adhesive type in both cement (100\%). Conclusion: Cleaning of the contaminated ceramic surface before adhesive cementation is an indispensable step in order to achieve a strong bond. Moreover, the removal of surface contaminants by sandblasting and Ivoclean paste can be considered efficient cleaning methods for zirconia surfaces.

\section{INTRODUCTION}

In the field of dentistry, ceramic has been widely used because it provided a restoration without metallic component, good esthetics, stability of shade, biocompatibility, high resistance to attrition and low thermo-conductibility. ${ }^{(1)}$ Among ceramics, zirconia has properties such as high strength, transformation toughening, chemical and structural stability, and biocompatibility; and these properties enabled zirconia prosthesis possible in posterior teeth area. ${ }^{(2-4)}$ But the zirconia ceramic has inert surface without glassy component, so it difficult to create durable bond to resin cement. ${ }^{(5,6)}$ Therefore, selection of an appropriate adhesive system to obtain good adhesion between the zirconia ceramic and the abutment is recognized to play a crucial role in the success of restorations. (7) However, bonding to zirconia ceramic is influenced by different factors; surface treatment of zirconia, the wettability of ceramic by adhesive resins, the composition of adhesive resins and a possible contamination during bonding. ${ }^{(8,9)}$ On the other hand, any alteration of the surface topography of zirconia results in changes on the surface area and on the wettability of the substrate, which are related to the surface energy and the adhesive potential. ${ }^{(10)}$

Wettability is the result of molecular interactions between the adhesive and the substrate, as well as the cohesion forces of the adhesive, particularly it surface tension. The wetting of the adherent surface by an adhesive could be indicated by the contact angle. ${ }^{(11)}$ Measurements of contact angles on the adherent surfaces provide information about surface free energies that relate to the bonding characteristics of the solids. ${ }^{(12)}$ The surface energy of a solid surface is greater than that of its interior where the interatomic distances are equal, and the energy is minimal. In fact, at the surface of the lattice, the energy is greater because the outermost atoms are not equally attracted in all directions. This increase in energy per unit area of surface $(\mathrm{J} / \mathrm{m} 2$ or $\mathrm{N} / \mathrm{m}$ ) is referred to as the surface energy or surface tension for liquids. Therefore, the surface atoms of a solid tend to form bonds to other atoms in close proximity to the surface, reducing the surface energy of the solid. Achieving an energy balance or the lowest energy state is the driving force for the chemical bond between the adhesive and the adhered. However, the surface energy and the adhesive qualities of a given solid can be reduced by any surface impurity or contaminant. ${ }^{(13)}$

A clean and dry surface ensures that the adhesive has the best possible chance of creating a proper bond with the adhered. ${ }^{(10)}$ Saliva, biofilm, and other organic debris are always present on the tooth surface. All of these contaminants reduce the surface energy of the bonding substrate and, consequently, its wettability. Therefore, it is very important for the surface that will contact the adhesive to be thoroughly clean to produce proper bonding strength to substrate ${ }^{(11)}$. The problems of saliva-protein contamination are still main problems during bonding of ceramic restorations. It is recommended to use different organic solution to remove the saliva contamination on luting surface of restoration before cementation. ${ }^{(14)}$ The composition of the cleaning agent should not cause any damages to the restoration surface and provide adhesive securing of dental restorative materials. In addition, it should be applied simply, washed off easily, non-toxic chemicals and has no negative effects on the fit of restoration. Millstein et al. suggested that alkaline cleaning agent is suitable for optimize the adhesive bond. ${ }^{(15)}$ While, previous studies have reported on different cleansing protocols, such as water ${ }^{(16)}$, alcohol (70\%-96\% isopropanol) ${ }^{(16,17)}$, phosphoric acid (37\%) ${ }^{(16-18)}$, and additional airborne particle abrasion $\left(\mathrm{Al}_{2} \mathrm{O}_{3}\right) \cdot{ }^{(19)} \mathrm{New}$ cleaning agent called Ivoclean, which is an alkaline suspension 
of zirconium oxide particles, was developed to remove the contamination from zirconia in an effort to clean the contaminated restoration surfaces and improve bonding to resin cements ${ }^{(20)}$, but there is little information regarding the use and its effect of this agent.

Therefore, this study was designated to evaluate the effect of different cleaning methods of contaminated zirconia surface on the surface free energy of zirconia ceramics and the shear bond strength of two resin cement to zirconia ceramics.
The null hypothesis was that saliva contamination would not affect neither the surface free energy zirconia ceramics, nor the shear bond strength of resin cement to zirconia surface.

\section{MATERIALS AND METHODS}

\section{I-Materials}

The material used in this study, their specification, composition, manufactures and batch numbers are summarized in table (1).

Table (1): Chemical compositions, manufacture, batch numbers of material used in the study.

\begin{tabular}{|c|c|c|c|c|}
\hline $\begin{array}{l}\text { Material } \\
\text { specification }\end{array}$ & Brand names & Composition & Manufacturer & $\begin{array}{l}\text { Batch } \\
\text { Number }\end{array}$ \\
\hline Zirconia & $\begin{array}{l}\text { Dental zirconia } \\
\text { ceramic }\end{array}$ & $\begin{array}{l}\text { Zinc oxide, Hafnium dioxide, Yttrium oxide, Aluminum } \\
\text { oxide and other oxides: }<0.5 \%\end{array}$ & Aidite-China & $\begin{array}{c}0197 \\
\mathrm{k} 111291\end{array}$ \\
\hline Clean paste & Ivoclean & $\begin{array}{l}\text { Zirconium oxide, water, polyethylene glycol, sodium } \\
\text { hydroxide, pigments,additives. }\end{array}$ & $\begin{array}{ll}\text { Ivoclar } & \text { Vivadent } \\
\text { Germany } & \end{array}$ & U55960 \\
\hline \multirow[t]{2}{*}{$\begin{array}{l}\text { Resin } \\
\text { Cement }\end{array}$} & $\begin{array}{l}\text { Multilink speed } \\
\text { Automix }\end{array}$ & $\begin{array}{l}\text { Base Paste } \\
\text { Urethane dimethacrylates, triethyleneglycol dimethacryl } \\
\text { ates,polyethyleneglycol dimethacrylate. } \\
\text { Catalyst Paste } \\
\text { ytterbium tri fluoride, urethane di methacrylate, } \\
\text { Triethylene glycol dimethacrylates, Methacrylate } \\
\text { phosphoric acid ester. } \\
\text { polyethylene glycol dimethacrylates, dibenzoyl peroxide. }\end{array}$ & Ivoclar Vivadent & U13871 \\
\hline & RelyX Ultimate & $\begin{array}{l}\text { Base Paste } \\
\text { Methacrylate monomers, Radiopaque, silanated fillers, } \\
\text { Initiator components, Stabilizers, Rheological additives. } \\
\text { Catalyst Paste } \\
\text { Methacrylate monomers, Radiopaque alkaline (basic) } \\
\text { fillers, Initiator, Components stabilizer, Pigments, } \\
\text { Rheological additives, Fluorescence dye. } \\
\text { Single bond } \\
\text { MDP Phosphate Monomer, Dimethacrylate resins } \\
\text { HEMA, Vitrebond }{ }^{\mathrm{TM}} \text { Copolymer } \\
\text { Filler, Ethanol, Water, Initiators, Silane }\end{array}$ & $\begin{array}{l}\text { 3M ESPE } \\
\text { Germany }\end{array}$ & 589109 \\
\hline \multicolumn{2}{|c|}{ Artificial saliva } & $\begin{array}{l}\mathrm{Na}-3 \mathrm{PO} 4(3.90 \mathrm{mM}), \mathrm{NaCl}(4.29 \mathrm{mM}), \mathrm{KCl}(17.98 \mathrm{Mm}) \text {, } \\
\mathrm{CaCl} 2(1.10 \mathrm{mM}), \mathrm{MgCl}(0.08 \mathrm{Mm}), \mathrm{H} 2 \mathrm{SO} 4(0.50 \mathrm{mM}), \\
\mathrm{NaHCO} 3(3.27 \mathrm{Mm}) \text { and distilled water the } \mathrm{pH} \text { adjusted } \\
\text { to } 7.2^{(21)}\end{array}$ & $\begin{array}{l}\text { Laboratory prepared } \\
\text { in Faculty of Science } \\
\text { Al-Azhar University }\end{array}$ & \\
\hline
\end{tabular}




\section{II- Methods:}

\section{Preparation of specimens}

A total of 80 specimens were copy milled from Yttrium-stabilized zirconia plates to produce zirconia specimens with the required dimensions (10 $\mathrm{mm} \times 10 \mathrm{~mm} \times 2 \mathrm{~mm}) .{ }^{(22-23)}$ The zirconia specimens were milled $20 \%$ larger than the desired dimensions to take into consideration shrinkage, and then the specimens were placed into furnace (Programat S1, Ivoclar Vivadent) to be sintered at $1500^{\circ} \mathrm{C}$ for 90 min according to the manufacturer's instructions to complete the crystallization process. All specimens were sandblasted with $50-\mu \mathrm{m}$ alumina for 15 seconds under 2.5 bars pressure and at a distance of $10 \mathrm{~mm}$ between the nozzle and the surface. ${ }^{(24,25)}$ The specimens were then cleaned in an ultrasonic bath with distilled water for $10 \mathrm{~min}$. ${ }^{(22)}$ Each ceramic specimen was then mounted in cold-curing acrylic resin. The acrylic resin was mixed and placed in split metallic mold and after initial polymerization, the zirconia specimens were placed on the surface of the acrylic resin.

\section{Saliva contamination:}

Each specimen, except for the control group was subjected for saliva contamination using artificial saliva solution before the bonding procedure. The artificial saliva was placed on the surface of zirconia specimens using microbrush at $37^{\circ} \mathrm{C}$ for $60 \mathrm{sec}$. Then the specimens were rinsed with distilled water spray for $15 \mathrm{sec}$ and dried with oil free air dryer spray for $30 \mathrm{sec} .{ }^{(26)}$

\section{Cleaning methods:}

The specimens were randomly divided into four groups, ( $\mathrm{n}=20$ specimens/gp), according to cleaning procedures. Group 1 (control): No saliva contamination before bonding procedure. Group 2: After saliva contamination, the surfaces of the specimens were rinsed with distilled water spray and air dried for 10sec. Group 3: After saliva contamination, the surfaces of specimens were treated with Ivoclean for $20 \mathrm{sec}$ using microbrush, rinsed with distilled water spray and air dried for 10sec. Group 4: After saliva contamination, the surface of specimens were subjected to resandblasting for 20 s, rinsed with distilled water spray, and air dried for 10sec. ${ }^{(22)}$ Each group was subdivided into 2 subgroups ( $n=10)$ according to the type of adhesive resin cement used (Multilink Speed and RelyX Ultimate). Each subgroup was further subdivided into two divisions $(\mathrm{n}=5)$ according to the type of test performed (contact angle and bond strength).

\section{Testing procedure:}

\section{Surface free energy $(\mathrm{mN} / \mathrm{m})$ measured by contact angle}

The surface free energies of zirconia specimens were determined by measuring the contact angle on the surface of specimen. Contact angles $(\theta)$ were measured by sessile drop technique ${ }^{(27)}$ at $23 \pm 1{ }^{\circ} \mathrm{C}$ for five specimens in each treatment group. The zirconia specimen in acrylic mold was positioned on a flat glass surface in the digital microscope (Scope Capture Digital Microscope, Guangdong, China).Controlled $(0.1 \mathrm{~mL})$ volume droplets of distilled water placed onto specimen surface by using of a micro-pipette, then images were captured immediately after deposition by using a micro video system, after that the acquired images were analyzed by Image J software (Image J, Earl F, Glynn II, Over Park, USA). The contact angle of each sample was measured by software drawing tangent line for liquid drop and another line parallel to zirconia surface. Values of angle between two tangent lines represented the value of contact angle (in figure 1). The surface free energy parameters of the solids were then determined on the basis of the Young's equation.

\section{Young's equation; $\gamma_{\mathrm{SL}}=\gamma_{\mathrm{S}}+\gamma_{\mathrm{L}} \cos \boldsymbol{\theta}_{\mathrm{L}}{ }^{(28)}$}

where, $\gamma_{\mathrm{SL}}$ is the interfacial solid-liquid free energy, $\gamma_{\mathrm{s}}$ is the solid surface free energy, which equal; $42.04 \mathrm{~mJ} / \mathrm{m}^{2(28)}, \gamma_{L}$ is the liquid surface tension (or free energy the liquid), which equal; $72.8 \mathrm{~mJ} / \mathrm{m}^{2(28)}, \boldsymbol{\theta}_{\mathbf{L}}$ is the contact angle. 


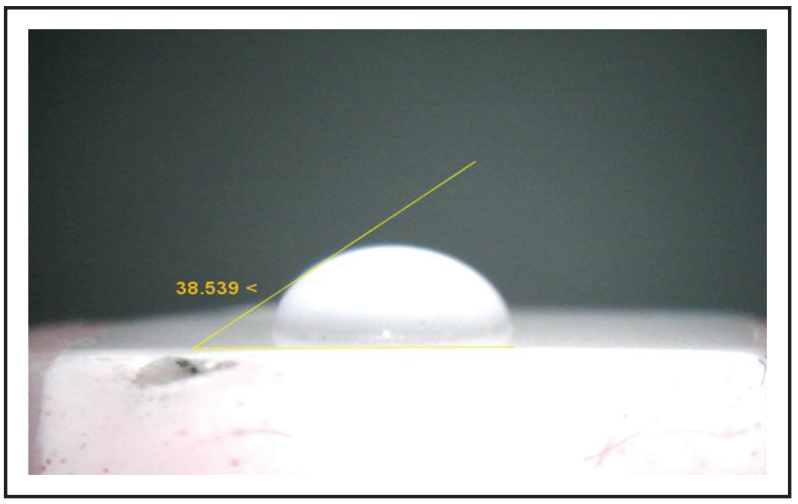

Fig. (1): Representative capture of contact angle measurement of zirconia specimen cleaned with water.

\section{Shear Bond Strength Testing}

A split Teflon mold with diameter $4 \mathrm{~mm}$ and thickness $2 \mathrm{~mm}{ }^{(29)}$ was used to shape the resin cement and to hold it in place on the specimens' surface until it set. Two resin cements were selected in this study with different bonding strategies, which were total etch RelyX ultimate and self-etch Multilink speed. The cement was condensed into the mold according to manufactures' instructions, the excess cement was then removed, the cement was covered by celluloid strip, then it was light cured (20 sec./surface) using Light curing light emitting diode (LED) with intensity $1000 \mathrm{~mW} / \mathrm{cm}^{2}$ (woodpeck, LED. Light, china). After the bonding procedure, all specimens were incubated in distilled water at $37^{\circ} \mathrm{C}$ for 24 hours.

All samples were individually and horizontally mounted on a computer controlled testing machine (Model 3345; Instron Industrial Products, Norwood, USA) with a load cell of $5 \mathrm{kN}$ and data were recorded using computer software (Blue hill Lite; Instron Instruments). Samples were secured to the lower fixed compartment of testing machine by tightening screws. Shearing test was done by compressive mode of load applied at Zirconia-resin interface using a half circle notch ended metallic rod attached to the upper movable compartment of testing machine traveling at cross-head speed of 0.5 $\mathrm{mm} / \mathrm{min}$ as shown in figure (2). The load required to debonding was recorded in Newton ${ }^{(22)}$.
Shear bond strength was calculated by dividing the load at failure to bonding area to express the bond strength in $\mathrm{MPa}{ }^{(11)} \tau=\mathrm{P} / \pi r^{2}$ where $; \tau=$ shear bond strength (MPa), $\mathrm{P}=\max$ load at failure $(\mathrm{N}), \pi$ $=3.14$ and $\mathrm{r}=$ radius of resin disc $(\mathrm{mm})$.

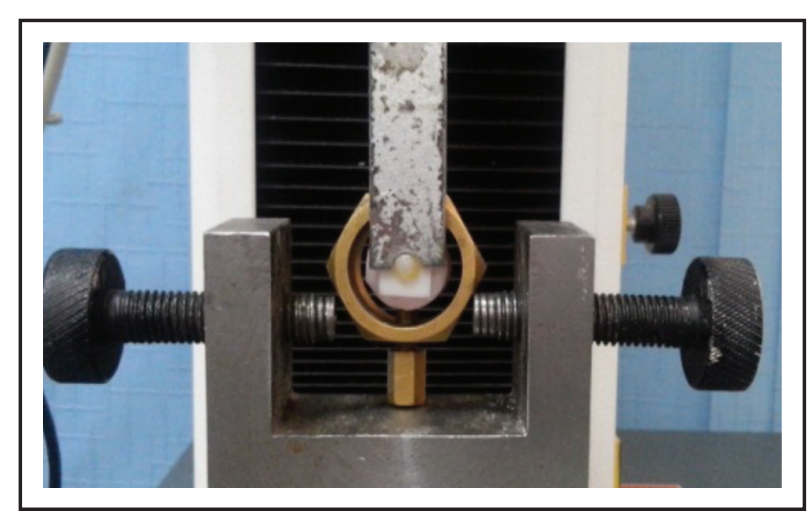

Fig. (2): Sample placed on universal testing machine

\section{Failure mode evaluation:}

After bonding test, all deboned zirconia specimens from all experimental subgroup were examined under an optical microscope at a magnification of $\times 65$ to define the location of bond failure. The failure mode of the individual sample was evaluated as one of three types: adhesive (failure at the adhesive interface), cohesive (failure within zirconia or cement) and mixed (adhesive and cohesive). ${ }^{(30)}$ The type of failure was determined on the basis of the percentage of substrate remaining material on zirconia surface.

Representative deboned zirconia sample from all tested subgroups was observed under environmental scanning electron microscope (ESEM) (QuantaTM 250 FEG, FEI company, Netherlands) computer controlled software Genesis using an accelerating voltage of 20-25 kVand magnification $14 x$ up to 1000000 , this to observe ultrastructure of the ceramic surface and define failure mode .

\section{Statistical analysis}

Data were analyzed by SPSS 16.0 (Statistical Package for Scientific Studies, SPSS, Inc., Chicago, 
IL, USA) for Windows, using one way analysis of variance (ANOVA) test was used to compare the 4 groups, followed by Tukey's post hoc test for multiple pairwise comparisons. Unpaired t test was used to compare between both cements. Pearson correlation test was used to study correlation between both parameters. The Pearson correlation coefficient is used to measure the strength of a linear association between two variables, where the value $r=1$ means a perfect positive correlation and the value $r=-1$ means a perfect negative correlation. The significance level was set at $p \leq 0.05$.

\section{RESULTS}

\section{Surface free energy $(\gamma)$}

Regarding the contact angle and the surface free energy, result revealed that there was a statistically significant difference between all tested groups $(\mathrm{p}<0.0001)$ as indicated by one way ANOVA test. The control groups record the lowest mean contact angle value $\left(25.81^{\circ} \pm 1.76^{\circ}\right)$ and the highest mean surface free energy value $(107.57 \mathrm{mN} / \mathrm{m})$. While the group washed with water revealed the highest mean contact angle value $\left(39.04^{\circ} \pm 0.68^{\circ}\right)$ and the lowest mean surface free energy value $(98.58 \mathrm{mN} / \mathrm{m})$ table2\&3,figure. Tukey' post hoc test revealed no significant difference between control, ivoclean and re-sandblasting groups. Whereas the group washed with water showed statistically significant difference with all other groups (table2, 3\& figure 3,4)

\section{Shear bond strength (MPa) of Multi-link speed and Rely-X ultimate cement:}

Regardless of the type of cement, results showed that the highest shear bond strength value was recorded for the control group $(14.33 \pm 1.98 \&$ $13.73 \pm 1.33 \mathrm{MPa})$, for Multi-link speed and Rely-X ultimate cement respectively, followed by re-sandblasting group, followed by ivoclean group, while the lowest shear bond strength value was recorded for the group washed with water $(10.9 \pm 0.53 \& 8.22 \pm 0.85 \mathrm{MPa})$ table (4) and figure (5). There was no significant difference between control, re-sandblasting and ivoclean group.

Regardless of the cleaning protocol groups, Multi-link speed cement recorded a higher mean shear bond strength value than RelyX Ultimate cement. However these difference was statistically non-significant except for the group washed with water $(\mathrm{p}=0.0003)$ as indicated by unpaired $\mathrm{t}$ test.

Table (2): Mean and SD of contact angle ${ }^{\circ}$ value of different groups

\begin{tabular}{|c|c|c|c|c|c|c|c|c|}
\hline \multicolumn{2}{|c|}{$\begin{array}{c}\text { Control } \\
(\mathrm{n}=5)\end{array}$} & $\begin{array}{c}\text { Washed with water } \\
(\mathrm{n}=5)\end{array}$ & Ivoclean & \multicolumn{2}{c|}{$\begin{array}{c}\text { Re-sandblasting } \\
(\mathrm{n}=5)\end{array}$} & P-value \\
\hline Mean & SD & Mean & SD & Mean & SD & Mean & SD \\
\hline $25.81^{\mathrm{b}}$ & 1.76 & $39.04 \mathrm{a}$ & .68 & $26.03 \mathrm{~b}$ & 2.46 & $26.54 \mathrm{~b}$ & 1.84 & $<0.001 *$ \\
\hline
\end{tabular}

Significance level $P<0.05$. Tukey's post hoc test: means with different superscript letters are significantly different

Table (3): Mean and SD of surface free energy $(\mathrm{mN} / \mathrm{m})$ value of different groups

\begin{tabular}{|c|c|c|c|c|c|c|c|c|}
\hline \multicolumn{2}{|c|}{$\begin{array}{c}\text { Control } \\
(\mathrm{n}=5)\end{array}$} & \multicolumn{2}{c|}{$\begin{array}{c}\text { Washed with water } \\
(\mathrm{n}=5)\end{array}$} & Ivoclean & \multicolumn{2}{c|}{$\begin{array}{c}\text { Re-sandblasting } \\
(\mathrm{n}=5)\end{array}$} & \multirow{2}{*}{$P$-value } \\
\cline { 1 - 5 } Mean & SD & Mean & SD & Mean & SD & Mean & SD \\
\hline $107.57 \mathrm{~b}$ & 7.33 & $98.58 \mathrm{a}$ & 2.83 & $107.45 \mathrm{~b}$ & 10.25 & $107.16 \mathrm{~b}$ & 17.66 & $<0.001 *$ \\
\hline
\end{tabular}

Significance level $P<0.05$. Tukey's post hoc test: means with different superscript letters are significantly different 


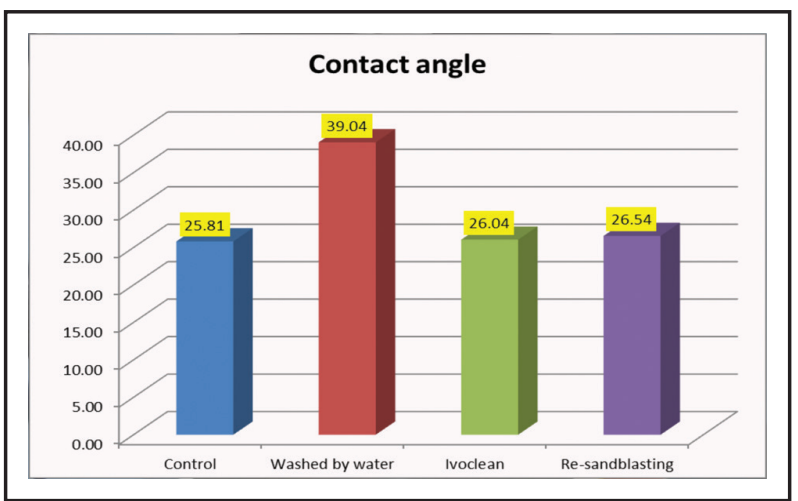

Fig. (3): Column chart showing mean contact angle values of different groups.

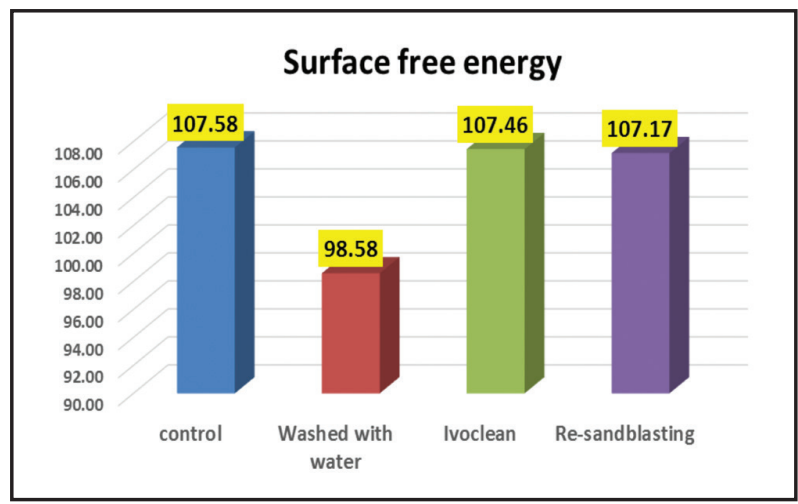

Fig. (4): Column chart showing mean surface free energy $(\mathrm{mN} / \mathrm{m})$ values of different groups.

Table (4): Mean and SD of shear bond strength (MPa) of different groups with the two cements

\begin{tabular}{|c|c|c|c|c|c|}
\hline \multirow[t]{2}{*}{ Groups } & \multicolumn{2}{|c|}{ Multi-link speed cement } & \multicolumn{2}{|c|}{ Rely-X ultimate cement } & \multirow{2}{*}{$\mathrm{P}$ value } \\
\hline & Mean & SD & Mean & SD. & \\
\hline Control & $14.32 \mathrm{a}$ & 1.98 & $13.72 \mathrm{a}$ & 1.32 & $0.588^{\mathrm{ns}}$ \\
\hline Washed with water & $10.90 \mathrm{~b}$ & .527 & $8.22 b$ & .846 & $0.0003^{*}$ \\
\hline Ivoclean & $13.58 \mathrm{a}$ & 1.19 & $12.75 \mathrm{a}$ & 3.23 & $0.6349^{\mathrm{ns}}$ \\
\hline Re-sandblasting & $14.15 \mathrm{a}$ & 1.54 & $12.20 \mathrm{a}$ & 1.81 & $0.1050^{\mathrm{ns}}$ \\
\hline P value & \multicolumn{2}{|c|}{$0.017 *$} & \multicolumn{2}{|c|}{$0.007 *$} & \\
\hline
\end{tabular}

Different letter in the same column indicating statistically significant difference $(\mathrm{p}<0.05)$

*; significant $(\mathrm{p}<0.05) \mathrm{ns} ;$ non-significant $(\mathrm{p}>0.05)$

\section{Correlation between both variables}

Table (5) and Figure (6) show Pearson's correlation test between all tested groups using two different cement. The results revealed that a weak negative correlation between contact angle and shear bond strength in control and ivoclean groups, these correlations are non-significant. While, the data collected from the 4 groups revealed a moderate negative correlation between contact angle and shear bond strength that was statistically significant $(\mathrm{p}<0.0007)$,
Table (5): Correlation between contact angle and

shear bond strength

\begin{tabular}{|c|c|c|c|}
\hline Group & $\mathrm{r}$ & Interpretation & P value \\
\hline Control & -0.2587 & Weak negative & $\begin{array}{c}0.675 \\
\text { (non significant) }\end{array}$ \\
\hline $\begin{array}{c}\text { Washed with } \\
\text { water }\end{array}$ & 0.268 & Weak positive & $\begin{array}{c}0.6629 \\
\text { (non significant) }\end{array}$ \\
\hline $\begin{array}{c}\text { Ivoclean } \\
\text { Re- } \\
\text { sandblasting }\end{array}$ & -0.3171 & Weak negative & $\begin{array}{c}0.603 \\
\text { (non significant) }\end{array}$ \\
\hline All groups & -0.6919 & $\begin{array}{c}0.759 \\
\text { negative }\end{array}$ & $\begin{array}{c}0.0007 * \\
\text { (significant) }\end{array}$ \\
\hline
\end{tabular}


Table (6): Failure mode frequency [number(\%)] in different groups and significance of the difference between groups (chi square test)

\begin{tabular}{|c|c|c|c|c|c|c|c|c|}
\hline Group & \multicolumn{2}{|c|}{$\begin{array}{l}\text { Control } \\
\text { (C) }\end{array}$} & \multicolumn{2}{|c|}{$\begin{array}{l}\text { Ivoclean } \\
\text { (IVO) }\end{array}$} & \multicolumn{2}{|c|}{$\begin{array}{c}\text { Re-sandblasting } \\
\text { (Re) }\end{array}$} & \multicolumn{2}{|c|}{ Washed with water(W) } \\
\hline $\begin{array}{l}\text { Failute } \\
\text { mode }\end{array}$ & $\begin{array}{l}\text { Multilink } \\
\text { (C1) }\end{array}$ & $\begin{array}{l}\text { RelyX } \\
\text { (C2) }\end{array}$ & $\begin{array}{c}\text { Multilink } \\
\text { (IVO1) }\end{array}$ & $\begin{array}{l}\text { RelyX } \\
\text { (IVO2) }\end{array}$ & $\begin{array}{l}\text { Multilink } \\
\quad(\operatorname{Re} 1)\end{array}$ & $\begin{array}{l}\text { RelyX } \\
(\operatorname{Re} 2)\end{array}$ & $\begin{array}{l}\text { Multilink } \\
\text { (W1) }\end{array}$ & $\begin{array}{l}\text { RelyX } \\
\text { (W2) }\end{array}$ \\
\hline Adhesive & $(20 \%)$ & $(40 \%)$ & $(20 \%)$ & $(40 \%)$ & $(40 \%)$ & $(20 \%)$ & $(100 \%)$ & $(100 \%)$ \\
\hline Cohesive & $(40 \%)$ & $(20 \%)$ & $(40 \%)$ & $(20 \%)$ & $(40 \%)$ & $(40 \%)$ & 0 & 0 \\
\hline Mixed & $(20 \%)$ & $(40 \%)$ & $(40 \%)$ & $(40 \%)$ & $(20 \%)$ & $(40 \%)$ & 0 & 0 \\
\hline $\mathrm{X}^{2}$ & \multicolumn{8}{|c|}{16.842} \\
\hline $\mathrm{P}$ & \multicolumn{8}{|c|}{$0.264^{\mathrm{ns}}$} \\
\hline
\end{tabular}

(1)Multi link speed cement, (2) RelyX Ultimate cement. Significance level $p<0.05$, non-significant

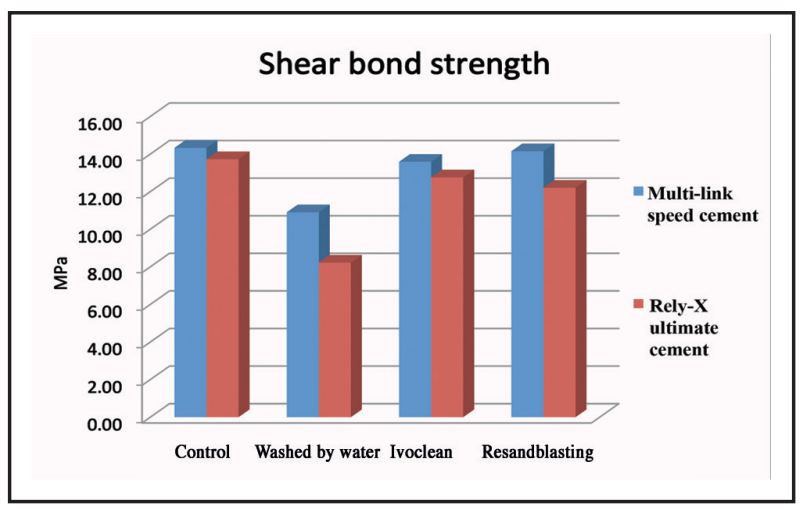

Fig. (5): Column chart showing comparison of mean shear bond strength values (MPa) using two different cements.

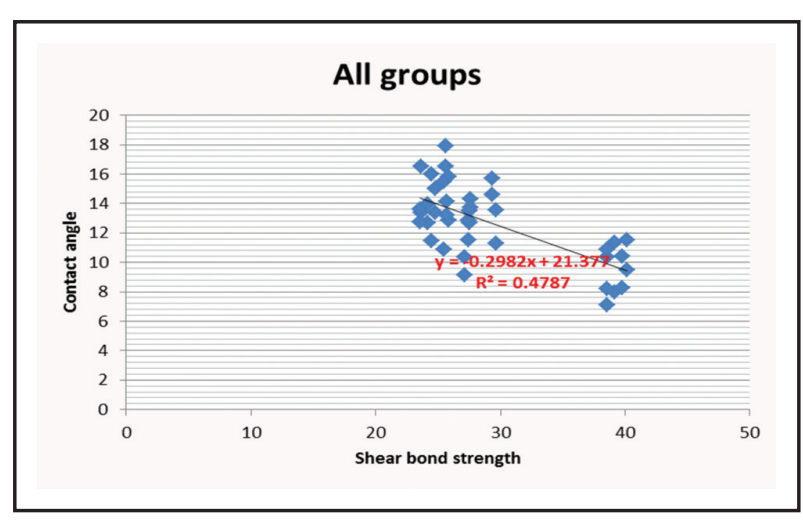

Fig. (6): Scatter plot showing correlation between contact angles and shear bond strength in all groups.

\section{Failure mode analysis:}

Failure mode for all groups was either adhesive, cohesive or mixed, with frequency ranging from 20 to $40 \%$ for each type of failure. The group washed with water showed that all of cases of failure were of the adhesive type in both cement (100\%). Chi square test revealed that the difference between groups was not statistically significant $(\mathrm{p}=0.264)$.

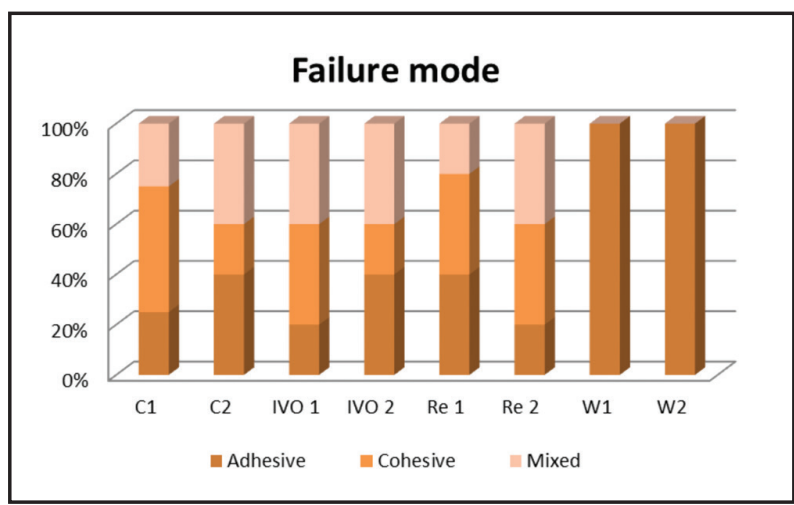

Fig. (7): Column chart showing failure mode frequency in different group 


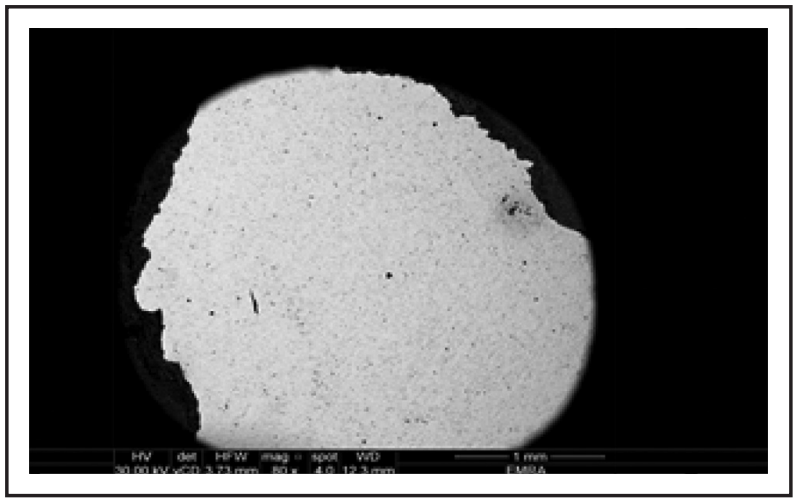

Fig. (8): SE photomicrograph at $80 x$, showing adhesive failure

\section{DISCUSSION}

The challenge in promoting a strong, reliable bond between the intaglios (ie, the internal surface of zirconia restorations to resin luting agents) lies in achieving a surface free of the contaminants that often result during intraoral try-in procedures. Therefore, surface cleaning procedures should be done before bonding, several cleaning solutions have been used for cleaning restorative surfaces such as water, alcohol, acetone.$^{(31)}$ In the present study, The effect of water, a fairly new cleaning paste (Ivoclean) and sandblasting on the resin/ zirconia SBS bond were evaluated.

The choice of ivoclean was based on the fact that Ivoclean consists of an alkaline suspension of zirconium oxide particles. Because of the size and concentration of the particles in the medium, phosphate contaminants are much more likely to bond to them than to the surface of the ceramic restoration. Ivoclean absorbs the phosphate contaminants like a sponge and thus leaves behind a clean zirconium oxide surface. Ivoclean allows effectively cleaning the saliva-contaminated bonding surfaces of restorations and thus create the basis for a strong, durable bond between the adhesive luting material and the restoration. ${ }^{(32)}$

The composition and mechanical properties of zirconia crystalline ceramics differ from those

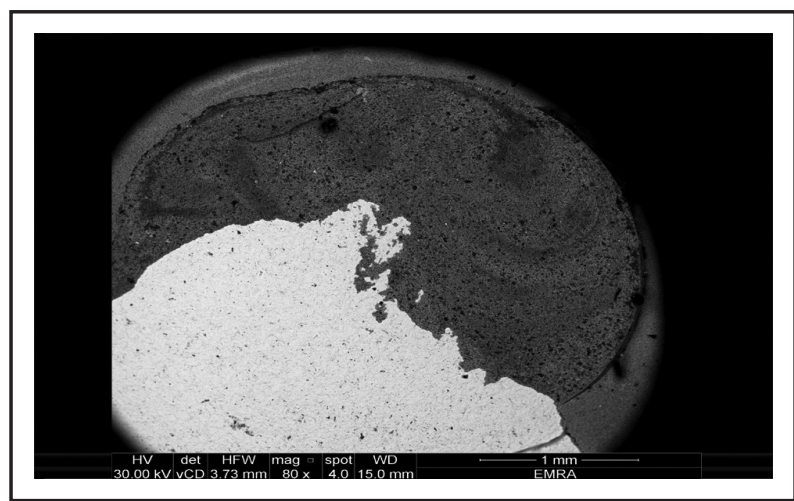

Fig. (9): SE photomicrograph at $80 x$ showing mixed failure

of classic ceramics. So, bonding to zirconia has become a topic of interest. A strong resin bond relies on micromechanical interlocking and chemical bonding to the ceramic surface. To obtain durable retention of zirconia restoration, various surface treatments should be carried out before cementation to improve the bond strength of resin cement to zirconia. Several treatments like sandblasting, acid etching, selective infiltration etching, surface coating, and laser irradiation have been studied in the recent years for adequate surface activation. ${ }^{\text {(33- }}$

${ }^{35)}$ In the present study sandblasting was chosen as a surface treatment because it is the most widely-used surface treatment method in dentistry. It has in fact been reported that sandblasting produces changes in the surface topography and surface roughness of zirconia and produce higher shear bond strength than others. ${ }^{(36,37)}$

Despite the good mechanical properties of zirconia, another major issue arises pertaining to bonding of ceramic restoration to resin cements, because zirconia does not contain silica and has resistance to acid corrosion due to its highly crystallized structure. (38) Different adhesive protocols were presented to the market in relation of adhesive resin cements. In the present study two types of adhesive resin cements were selected. Multilink Speed cement and RelyX Ultimate cement, 
and their selection were based on manufacture recommendations. Self-adhesive cements are the latest introduced subgroup of resin cements. They simplified the luting procedures by being directly applied on the tooth structure and the ceramic substrate without need to previous treatment. In addition, they are claimed to reduce post-operative sensitivity that produced by total etch resin cements.

Multilink Speed contains an adhesive monomer which has been specifically formulated to endow the cement with self-adhesive properties. This monomer consists of a long-chain methacrylate with a phosphoric acid group. The phosphoric acid group enables a stable chemical bond to zirconium oxide and many metals. While, RelyX Ultimate cement is a dual cure, adhesive resin cements. The cement was designed for optimal performance when combined with single bond universal adhesive. This adhesive bonding is based on two factors, one micromechanical and the other chemical. The micromechanical component refers to the interlocking of the resin cement with the previously-treated roughened ceramic surface. The chemical component is based on a chemical bond between the two materials produced by silane or 10-methacryloyloxydecyl dihydrogen phosphate (MDP). ${ }^{(39-40)}$

Results of the present study showed that the control group recorded lowest contact angle value and the highest mean surface free energy value which indicated good wettability of zirconia surface as shown in table (2\&3) and Figure (3\&4). While ivoclean and re-sandblasting group showed higher contact angle (lower surface free energy) than control group but the difference was nonsignificant, this may be attributed to the fact that Saliva consists of phosphate groups in the form of phospholipids, which actively bond to the internal surface of restorations ${ }^{(22)}$.

For ivoclean group, according to the manufacturer's scientific documentation, Ivoclean contains zirconia oxide, water, polyethylene glycol, sodium hydroxide, and other additive ${ }^{(32)}$. Phosphate contaminants on the ceramic surface are more likely to bond to the particles in Ivoclean than to the ceramic surface because the size and concentration of the particles were adjusted for this purpose. In accordance with this theory, Ivoclean might absorb the phosphate contaminants and leave behind a clean zirconium oxide surface. The initial bond strength was lower in the Ivoclean group than in the control group, but the difference was not significant $(20,22)$.

For re-sandblasting group, sandblasting causes a new surface layer, underlying the top bonding surface, to be exposed. This new surface layer is high in purity and activity ${ }^{(41)}$. By virtue of its (zirconia ceramic after sandblasting) high surface energy, it has a high tendency to attract and combine with other chemical compounds, which then causes its surface energy to decrease. ${ }^{(42)}$

On the other side, the group washed with water recorded highest mean contact angle value and the lowest surface free energy value which showed statistically significant difference with all other group. This may be explained by the fact that water rinsing alone is not sufficient to remove saliva contamination. Saliva contains more than 99\% water, combined with small amounts of proteins, glycoprotein sugars, amylase, and inorganic particles. After saliva contamination, non-covalent adsorption of salivary proteins occurs on the surfaces of restorative materials, creating an organic coating that cannot be removed by rinsing with water ${ }^{(43)}$. These results are in agreement with that of previous studies, which showed reduced wettability due to increased contact angle measurement after saliva contamination of ceramic surfaces ${ }^{(22,44)}$

Results of the shear bond strength showed that the highest shear bond strength value was recorded for the control group, followed by resandblasting group, followed by ivoclean group. 
While the lowest shear bond strength value was recorded for the group washed with water, table (4) and figure(8). There was no significant difference between control, re-sandblasting and ivoclean group.Generally, this could be attributed to saliva contamination that adversely affects resin bonding because organic deposits remain on the restorative materials after the first few seconds of exposure to saliva. ${ }^{(45)}$ These findings were in accordance with previous studies that revealed that contamination inhibits the formation of stable bond of ceramic and significantly decrease in bond strength. For this reason, ceramic surface should be cleaned prior to cementation. ${ }^{(20,22,29,31)}$

On the other hand, the mean shear bond strength value in the group washed by water was significantly lower than all other groups.This result was also supported by ESEM that showed a predominant adhesive failure mode. Therefore, the null hypothesis that saliva contamination has no influence on the bonding of the resin cement to zirconia ceramics or on surface free energy should be rejected

Regardless of the cleaning protocol groups, Multi-link speed cement showed statistically nonsignificant different in mean shear bond strength value with Rely X Ultimate cement,shown in table (4) and figure (5), this could be due to the adhesive potential of Multilink Speed cement that eliminate the need for an additional bonding agent or primer. As they comprise a phosphoric acid monomer, bonding to zirconium oxide can be achieved without having to condition this substrate with a bonding agent ${ }^{(46)}$.

Moreover, Multilink Speed cement contains an adhesive monomer consisting of a long-chain methacrylate with a phosphoric acid group in its composition. This chain is able to establish a stable chemical bond to zirconium oxide as it is self-adhesive resin cement ${ }^{(47)}$. Multilink Speed has shown to be fairly tolerant of moisture; however, users should make sure that the surfaces are not contaminated with blood or residues of other dental treatment materials, which may have an adverse effect on adhesion These results are in accordance with previous studies. ${ }^{(46,48)}$ Also, this was supported by the result of ESEM as the predominant failure mode for Multilink Speed cement was cohesive failure comparable to Rely X Ultimate, as showed in table (6) and figure (8\&9), which directly reflects its capacity for bonding to zirconia.

The statistically insignificant difference in shear bond strength test results between the two tested cements could be attributed to their chemical composition where both cements are based on the presence of methacrylate monomers containing phosphoric acid groups responsible for bonding to zirconia.

As Rely X Ultimate cement contains bifunctional methacrylate, it was used with Single Bond Universal adhesive uses three trusted and well known adhesion promoters in one formulation (VMS technology) and thus also bonds to restoration substrates. This was supported by Petrauskaset etal: who showed that chemical reaction between the phosphate monomer (MDP) present in the RelyX resin cement and the oxide layer present on the zirconium oxide ceramic surface has been reported as responsible for improving adhesion between resin cements and ceramics made with zirconium oxide. ${ }^{(49)}$

Regarding the results that revealed a negative correlation between contact angle and shear bond strength in grouping the data collected from the 4 groups. And these correlations were significant, table(5) and Figure (6). According to the contact angle measurements, groups (control, ivoclean and re-sandblasting) which produced higher bond strength values, showed lower mean contact angle values and therefore indicated more hydrophilic surfaces. On the contrary, group washed with water, which exhibited lower bond strength values, yielded higher contact angle values and indicated 
more hydrophobic surfaces. Thus, more hydrophilic zirconia surfaces indicate more effective cleaning; whereas more hydrophobic surfaces indicate lesseffective cleaning ${ }^{(50)}$.

\section{CONCLUSIONS}

Within the limitation of this in vitro study the following conclusions can be made:

1. Cleaning of the contaminated ceramic surface before adhesive cementation is an indispensable step in order to achieve a strong bond.

2. The removal of surface contaminants by sandblasting and Ivoclean paste can be considered efficient cleaning methods for zirconia surfaces.

\section{REFERENCES}

1. Odén A, Andersson M, Krystek-Ondracek I, Magnusson D. Five-year clinical evaluation of Procera AllCeram crowns. J Prosthet Dent. 1998;80:450-6

2. Kern M, Wegner SM. Bonding to zirconia ceramic: adhesion methods and their durability. Dent Mater. 1998; 14:64-71.

3. Kosmac T, Oblak C, Jevnikar P, Funduk N, Marion L. The effect of surface grinding and sandblasting on flexural strength and reliability of Y-TZP zirconia ceramic. Dent Mater. 1999; 15:426-33.

4. Borges GA, Sophr AM, de Goes MF, Sobrinho LC, Chan DC. Effect of etching and airborne particle abrasion on the microstructure of different dental ceramics. J Prosthet Dent. 2003; 89:479-88.

5. Della Bona A, Anusavice KJ, Mecholsky JJ. Failure analysis of resin composite bonded to ceramic. Dent Mater 2003; 19:693-9.

6. Valandro LF, Della Bona A, Antonio Bottino M, Neisser MP. The effect of ceramic surface treatment on bonding to densely sintered alumina ceramic. J Prosthet Dent 2005; 93: 253-9.

7. Papia E, Larsson C, du Toit M, Vult von Steyern P. Bonding between oxide ceramics and adhesive cement systems: A systematic review. J Biomed Mater Res B Appl Biomater .2014; 102: 395-413
8. Inokoshi M, Kameyama A, De Munck J, Minakuchi S, Van Meerbeek B. Durable bonding to mechanically and/ or chemically pre-treated dental zirconia. J Dent 2013; 41: $170-19$

9. Wolfart M, Lehmann F, Wolfart S, et al. Durability of the resin bond strength to zirconia ceramic after using different surface conditioning methods. Dent. Mater. 2007; 23:45-50.

10. Bona A D, Oscar E. Pecho Alessandretti R. Zirconia as a Dental Biomaterial. Materials (Basel). 2015; 8: 4978-91.

11. Sakaguchi R L, Powers J M. Craig's restorative dental materials.2012;13th ed:327-29

12. Asmussen E, Peutzfeldt A. Resin composites: strength of the bond to dentin versus surface energy parameters. Dent Mater 2005; 21: 1039-43.

13. Della Bona A., van Noort R. Shear vs. tensile bond strength of resin composite bonded to ceramic. J. Dent. Res. 1995;74:1591-96

14. Rosenstiel SO, Land MF, Fujimoto J. Contemporary fixed prosthodontics. 2nd ed. St. Louis: Mosby; 1995;.622

15. Millstein PL, HO JC, Naim W, Nathanson D. Effect of a silicone fit-indicator on crown retention in vitro. J Prosthet Dent 1989; 62: 510-11.

16. Yang B, Lange-Jansen H, Scharnberg M, Wolfart S, Ludwig $\mathrm{K}$, Adelung $\mathrm{R}$, et al. Influence of saliva contamination on zirconia ceramic bonding. Dent. Mater. 2008; 24: 508-13.

17. Zhang S, Kocjan A, Lehmann F, Kosmač T, Kern M. Influence of contamination on resin bond strength to nanostructured alumina-coated zirconia ceramic. Eur J Oral Sci 2010;118:396-403

18. Nishigawa G, Maruo Y, Irie M, Oka M, Yoshihara K. Ultrasonic cleaning of silica-coated zirconia influences bond strength between zirconia and resin luting material. Dent. Mat.J. 2008; 27:842-8.

19. Feitosa SA, Patel D, Bottino MA , O”zcan M, Bottino MC, Valandro LF, et al Effect of Cleansing Methods on Saliva-Contaminated Zirconia-An : Evaluation of Resin Bond Durability. Oper. Dent. 2014; 39-6.

20. Brown DT, Platt J A, Srinivasan M, Bottino MC, Levon $\mathrm{J}$ A. Influence of saliva contamination on resin bond durability to zirconia - effect of cleaning methods, Indiana University School of Dentistry, 2015. 
21. Castellan CS, Pereira PN, Grande RH, Bedran-Russo AK. Mechanical characterization of proanthocyanidin-dentin matrix interaction, Dent Mater; 26:968-73, 2010.

22. Ishii R, Tsujimoto A, Takamizawa T, Tsubota K, Suzuki T, Shimamura Y, et al. Influence of surface treatment of contaminated zirconia on surface free energy and resin cement bonding. Dent Mater J 2015; 34: 91-7

23. Nishigori AA, Yoshida T, Bottino MC, Platt JA, Plattsushi Nishigori JA.Influence of zirconia surface treatment on veneering porcelain shear bond strength after cyclic loading. J Prosthet Dent 2014; 112: 1392-8.

24. Ozcan M, Melo RM, Souza RO, Machado JP, Felipe Valandro L, Botttino MA. Effect of air-particle abrasion protocols on the biaxial flexural strength, surface characteristics and phase transformation of zirconia after cyclic loading. J Mech Behav Biomed Mater. 2013; 20:19-28.

25. Souza RO, Valandro LF, Melo RM, Machado JP, Bottino MA, Ozcan M. Air-particle abrasion on zirconia ceramic using different protocols: effects on biaxial flexural strength after cyclic loading, phase transformation and surface topography. J Mech Behav Biomed Mater. 2013; 26:155-63.

26. Preetha A. and Banerjee R. Comparison of Artificial Saliva Substitutes. Trends Biomater. Artif. Organs, January 2005; $18: 178-86$

27. Hu X, Ling J, Gao Y. Effects of Irrigation Solutions on Dentin Wettability and Roughness. J Endod, 2010; 36: 1064-7.

28. Gonzalez-Martin ML, Labajos-broncano L, Janczuk B.,Bruque J.M. Wettability and surface free energy of zirconia ceramics and their constituents. J mat sci 1999; 34 :5923 - 26

29. Quaasa AC, Yangb B, Kernb M. Panavia F 2.0 bonding to contaminated zirconia ceramic after different cleaning procedures. Dent. Mater. 2007; 23: 506-12.

30. El-Shrkawy ZR, El-Hosary MM, Saleh O, Mandour MH. Effect of different surface treatments on bond strength, surface and microscopic structure of zirconia ceramic . FDJ. 2016; 2: 41-53.

31. Doungsri J and Arksornnukit M. Effect of cleaning solutions on shear bond strength of resin cement to saliva contaminated lithium disilicate eramic. International Graduate Research Conference 2013.

32. Scientific documentation Ivoclean.
33. Blatz MB, Sadan A, Martin J, Lang B. In vitro evaluation of shear bond strengths of resin to densely-sintered highpurity zirconium-oxide ceramic after long-term storage and thermal cycling. J. Prosthet. Dent. 2004; 91: 356-62.

34. Yang B, Barloi A, Kern M. Influence of air-abrasion on zirconia ceramic bonding using an adhesive composite resin. Dent. Mater. 2010; 26:44-50.

35. Kern M, Wegner SM. Bonding to zirconia ceramic: adhesion methods and their durability. Dent. Mater. 1998; 14: 64-71

36. Miyazaki T, Nakamura T, Matsumura H, Ban S, Kobayashi T. Current status of zirconia restoration. J Prosthodont Res. 2013; 57: 236-61.

37. Casucci A, Osorio E, Osorio R, Monticelli F, Toledano M, Mazitelli C, et al. Influence of different surface treatments on surface zirconia frameworks. J. Dent. 2009; 37: 891-97.

38. Thompson JY, Stoner BR, Piascik JR, Smith R. Adhesion/ cementation to zirconia and other non-silicate ceramics: where are we now? Dent. Mater. 2011; 27: 71-82.

39. Román-Rodríguez JL, Roig-Vanaclocha A, Fons-Font A, GranellRuiz M, Solá-Ruiz MF, Amigó-Borrás V, et al. In vitro experimental study of bonding between aluminium oxide ceramics and resin cements. Med. Oral Patol. Oral Cir Bucal. 2010; 15: 95-100.

40. Tanaka R, Fujishima A, Shibata Y, Manabe A, Miyazaki T. Cooperation of phosphate monomer and silica modification on zirconia. J. Dent. Res. 2008; 87: 666-670.

41. Castle JE. The composition of metal surfaces after atmospheric exposure: An historical perspective. J. Adhesion. 2008; 84: 368-88.

42. Nishigawa G, Maruo Y, Irie M, Maeda N, Yoshihara K, Nagaoka N, et al. Various Effects of Sandblasting of Dental Restorative Materials.J pone.2016; 0147077

43. Phark JH, Duarte Jr S, Kahn H, Blatz MB, Sadan A. Influence of contamination and cleaning on bond strength to modified zirconia. Dent. Mater. 2009; 25:1541-50.

44. Kim D, Son J, Jeong S, Kim Y, Kim K, Kwon T-Y. Efficacy of various cleaning solutions on saliva-contaminated zirconia for improved resin bonding . J.Adv. Prosthodont. 2015; 7: 85-92.

45. Carlen A, Nikdel K, Wennerberg A, Holmberg K, Olsson J. Surface characteristics and in vitro biofilm formation on glass ionomer and composite resin. Biomaterials. 2001; 22: 481-87.

46. Scientific documentation MultiLink Speed. 
47. Gamal R, Gomaa YF, Abdellatif MA. Microtensile bond strength and scanning electron microscopic evaluation of zirconia bonded to dentin using two self-adhesive resin cements; effect of airborne abrasion and aging. Future Dent. J. 2017; 3: 55-60.

48. Valandro LF, Ozcan M, Amaral R, Vanderlei A, Bottino MA. Effect of testing methods on the bond strength of resin to zirconia-alumina ceramic: microtensile versus shear test. Dent. Mater. 2008; 27: 849-55.
49. Petrauskas A, Novaes Olivieri K A, Mendes Pupo Y, Berger G, Gonçalves Betiol E A. Influence of different resin cements and surface treatments on microshear bond strength of zirconia-based ceramics. J. Conserv. Dent. 2018; 21: 198-204.

50. Murthy V, Balaji M, Livingstone D. Effect of Four Surface Treatment Methods on the Shear Bond Strength of Resin Cement to Zirconia Ceramics- A Comparative in Vitro Study. J Clin Diagn Res. 2014; 8: 65-68. 